\title{
Improving the sustainability of cement production by using numerical simulation of limestone thermal degradation and pulverized coal combustion in a cement calciner
}

\author{
Hrvoje Mikulčić*, Milan Vujanović, Neven Duić \\ Faculty of Mechanical Engineering and Naval Architecture, University of Zagreb, Zagreb, Croatia
}

\section{A R T I C L E I N F O}

\section{Article history:}

Received 24 November 2013

Received in revised form

31 March 2014

Accepted 4 April 2014

Available online $\mathrm{xxx}$

\section{Keywords:}

Sustainable cement production

Coal combustion

Calcination process

Cement calciner

Numerical modelling

\begin{abstract}
A B S T R A C T
The cement industry sector is one of the largest carbon emitting industrial sectors, and due to the effect of global warming sustainable cement production is increasingly gaining on importance. Controlling the combustion of coal and the thermal degradation of limestone, the two main thermo-chemical processes that occur inside a cement calciner, is of significant importance, since these processes have a direct influence on the cement quality, pollutant formation and overall energy efficiency of the cement manufacturing process. One of the possibilities for the improvement and control of these thermochemical processes are Computational Fluid Dynamics - CFD simulations. The results gained from these simulations are being increasingly used to enhance the efficiency of cement production, since they improve the understanding of the flow characteristics and transport phenomena taking place inside the cement calciner. The purpose of this paper is to present that a more energy efficient and sustainable cement production can be achieved by deploying CFD simulations in the process of cement production. The numerical models of limestone thermal degradation, also known as the calcination process, and pulverized coal combustion were developed and implemented within the commercial computational fluid dynamics code FIRE, which was then used for the analysis. The developed models are based on the solution of Navier-Stokes equations for the gas phase, and on the Lagrangian dynamics for the discrete particles. A three dimensional complex geometry of a real industrial cement calciner was used for the CFD simulation. The information obtained from this numerical simulation, such as the distribution of particles, distribution of temperatures and the concentrations can be used for better understanding of particle kinetics and pollutant emissions from the given cement calciner and also for its further investigation and optimization.
\end{abstract}

(ㄷ) 2014 Elsevier Ltd. All rights reserved.

\section{Introduction}

Over the past five decades rapid increases in the concentrations of greenhouse gases - GHG in the atmosphere, mainly coming from the industrial sector, have resulted in global climate changes (IPCC, 2007). Due to this reason, cleaner and more sustainable production is becoming more and more important within all industrial sectors (Klemeš et al., 2012). The cement industry sector as an energy intensive industrial sector, where energy costs represent approximately $40 \%$ of the total production costs per ton of cement (Zhang et al., 2013), and one of the highest GHG emitting industrial sectors,

\footnotetext{
* Corresponding author. Tel.: +38516168 494; fax: +38516156940.

E-mail addresses: hrvoje.mikulcic@fsb.hr (H. Mikulčić), milan.vujanovic@fsb.hr (M. Vujanović), neven.duic@fsb.hr (N. Duić).
}

accounts for around 5\% of global anthropogenic GHG emissions (Wang et al., 2013). Therefore, improvement in energy efficiency is becoming increasingly important for fulfilling the $\mathrm{CO}_{2}$ emissions limitations coming from this industrial sector (Dovì et al., 2009).

Currently, the most energy efficient technology for cement production is a dry rotary kiln process with a multi-stage preheater and a cement calciner (Benhelal et al., 2013). The latter, cement calciner, is a pyroprocessing unit found in front of the rotary kiln, and inside of which the raw material, mainly composed of limestone, undergoes the calcination process. The calcination process is a strong endothermic reaction that requires combustion heat released by the fuel, indicating that endothermic limestone calcination and exothermic fuel combustion proceed simultaneously (Mikulčić et al., 2013a). Controlling of these two thermo-chemical processes is of significant importance, since they have a direct influence on the cement quality, pollutant formation and overall 
energy efficiency of the cement manufacturing process. There are various approaches for controlling and improving of the energy efficiency within industrial furnaces. However, using CFD simulations (Klemeš et al., 2010) to investigate and improve thermochemical processes is becoming increasingly important. Together with experiments and theory, CFD simulations have become an integral component of pyroprocessing unit's research. The results gained from CFD simulations can be used for the optimization of turbulent reacting fluid flow, the design of the pyroprocessing unit, and finally for the enhancement of the fuel efficiency, e.g. energy efficiency, making the cement production more sustainable.

Several studies have examined some of the numerical aspects of complex multiphase flow inside cement calciners. Oh et al. (2004) analyzed the turbulent gas-particle flow, coal combustion and heat transfer within a cement calciner. Their work showed that the numerically predicted results agreed well with the measured results. Hillers et al. (2005) numerically investigated processes that occur in cement calciners, e.g. they modelled the turbulence, radiation, calcination process, coal combustion, and NOx formation. Their study showed that CFD shows a great potential regarding emission control and fuel savings. Zheng et al. (2005) studied the effects of primary jet velocity and throat diameter on the twophase gas-solid flow inside a cement calciner. Their study showed that for the simulated cement calciner, these two effects have a strong influence on flow structure and particle concentration. Dou et al. (2009) investigated the coal combustion and the decomposition of raw material inside a cement calciner. Their work showed that in order to increase the raw material decomposition and optimise the temperature inside the calculated cement calciner, the direction of the tertiary inlet needs to be tangentially adjusted, and that the raw material inlet needs to be opposite the coal inlet. Ha et al. (2010) studied the separation of coal particles and its corresponding influence on the decomposition of limestone inside a cement calciner. Their study showed that by combusting finer coal particles a negligible influence can be observed on the decomposition of limestone. Nance et al. (2011) using the mineral interactive computational fluid dynamics investigated the "HotReburn" conditions inside a cement calciner. Their work showed that the proposed method greatly assists in the optimization of a cement calciner's operating conditions and design. Mikulčić et al. (2013a) numerically studied the impact of different inlet mass flows and fuel amounts, on the coal burnout rate, limestone decomposition rate, and pollutant emissions. Their study showed that CFD is a useful tool for a cement calciner's process optimization. All of these studies show that despite ongoing efforts in the development of both physical and chemical modelling, CFD simulation of the complex multiphase flow inside the cement calciners cannot as yet be considered fully predictive on a quantitative level and further research is required.

The processes occurring inside a cement calciner have a direct influence on cement quality, pollutant formation and the overall energy efficiency of the cement manufacturing process. Appropriate numerical models need to be used to numerically study the role and interaction of pulverized coal combustion and limestone calcination within a cement calciner. In this study a numerical model of pulverized coal combustion was developed and implemented within the commercial finite volume based CFD code FIRE. This code was used to simulate turbulent fluid flow, temperature field, species concentrations and the interaction of particles with the gas phase inside the complex three dimensional geometry of a real cement calciner, by solving the set of mathematical equations that govern these processes. The numerical model is based on the solution of Navier-Stokes equations for the gas phase, and on the Lagrangian dynamics for the discrete particles. Actual plant data were used to verify the accuracy of the modelling approach. The test of the numerical model's accuracy yielded satisfactory results and proper trends for the coal burnout rate as well as limestone degradation rate. The results gained by this real-plant example show that for better understanding of fluid flow, transport phenomena, and the thermo-chemical reactions taking place inside the cement calciner, the proposed model is a useful tool for investigation. Furthermore, the proposed model can assist in the improvement of the specific local conditions for the calcination process, the overall optimization of cement calciner's operating conditions, reduction of pollutant emissions, and the improvement of the cement calciner's design.

\section{Numerical model}

The continuous phase is described by solving conservation equations using the Eulerian formulation. These equations are based on the conservation laws for mass, momentum and energy. They are obtained by using the finite volume approach, where the fluid flow is divided into a number of control volumes and a mathematical description is developed for the finite control volume. The general form of conservation equation is fundamentally derived in integral form, taking into consideration the total amount of some property within the control volume:

$$
\int_{V} \frac{\partial}{\partial t}(\rho \varphi) \mathrm{d} V+\int_{S}(\rho \varphi) u_{j} n_{j} \mathrm{~d} S=\int_{S}\left(\Gamma_{\varphi} \frac{\partial \varphi}{\partial x_{j}}\right) n_{j} \mathrm{~d} S+\int_{V} S_{\varphi} \mathrm{d} V
$$

where $t$ is the time, $\rho$ is the density, $V$ is the volume, $S$ is the surface, $u_{j}$ velocity, $n_{j}$ normal vector, $x_{j}$ Cartesian coordinates, $\Gamma_{\varphi}$ diffusion coefficient, and $S_{\varphi}$ is the source term of the dependent variable $\varphi$. In Eq. (1) the first term is an unsteady term, the second term is convection, the third term is diffusion and the last term is source or sink. The first term on the left hand side represents the rate of change of the scalar property $\varphi$ in the control volume. The second term on the left hand side is the net convective flux of this property across the control volume boundaries. The first term on the right hand side is the net diffusive flux across the control volume boundaries. The final term on the right hand side is the source or sink of the property $\varphi$. Two transport mechanisms can be distinguished across the control volume boundaries: convection transport due to the motion of the fluid, and diffusion - transport due to the differences in concentration.

The motion and transport of the solid particles are tracked through the flow field using the Lagrangian formulation. Solid particles are discretized into finite numbers of particle groups, known as particle parcels, which are supposed to have same size and also the same physical properties. The trajectory of each particle parcel within the flow field is calculated using the Lagrangian scheme, which means that representative parcels are tracked by using a set of equations that describe their dynamic behaviour as they move through the calculated flow field. Furthermore, the equations of motion for each particle parcel based on the Lagrangian approach are coupled with the Eulerian representation of the continuous phase. This allows the decomposition of complicated and highly nonlinear systems of transport equations and describes the interactions between the control volumes and the system of equations that govern processes in individual control volumes, including the exchange between the solid particles and the gas phase. The systems of these equations are mainly integrated using a much shorter time step than the global time steps that are used for calculation of the gas phase. The coupling between the parcels and the gaseous phase is taken into account by introducing appropriate source terms for mass, momentum and enthalpy exchange. 
The heterogeneous reactions of the mathematical model used for the calcination process, coal combustion calculation are treated in the Lagrangian spray module, where thermo-chemical reactions occur inside a particle involving particle components and gas phase species. The homogeneous reactions used for the coal combustion calculation are treated in the gas phase using the Eulerian formulation. In order to simulate the named thermo-chemical reactions properly, the developed models were integrated into the commercial CFD code via user-functions written in the FORTRAN programming language (FIRE, 2011).

\subsection{Calcination process}

Calcination is an industrial process that uses high temperature to change the chemical and physical properties of limestone, a sedimentary rock composed of the mineral calcite - calcium carbonate and other mineral dolomites. The calcination process is used in many different industries today, such as cement, chemical, pharmaceutical and sugar industry, where limestone $\mathrm{CaCO}_{3}$ is converted by thermal decomposition into lime $\mathrm{CaO}$ and carbon dioxide $\mathrm{CO}_{2}$. This reaction is highly endothermic and requires combustion heat released by the fuel where the temperature is between $780{ }^{\circ} \mathrm{C}$ and $1350{ }^{\circ} \mathrm{C}$, indicating that endothermic limestone calcination and exothermic fuel combustion proceed simultaneously. The following equation is used to present the calcination process:

$\mathrm{CaCO}_{3}(\mathrm{~s}) \stackrel{+178 \mathrm{~kJ} / \mathrm{mol}}{\longrightarrow} \mathrm{CaO}(\mathrm{s})+\mathrm{CO}_{2}(\mathrm{~g})$.

The previously developed and validated numerical model was used to describe the calcination process (Mikulčić et al., 2012). In the developed model, limestone calcination reaction is calculated using the Arrhenius rate equation for the liberation of $\mathrm{CO}_{2}$ from the particle. The model takes into account the effects of temperature, decomposition pressure, diffusion, and particle porosity since dissociation of the limestone begins at the outer surface of the limestone particle and shifts inward, leaving a porous layer of lime at the surface.

\subsection{Pulverized coal combustion}

Pulverized coal combustion is a very significant mode of fuel utilization the cement industry. Due to the increase of environmental awareness, and the need for more sustainable coal utilization, plant operators are trying to lower greenhouse gas emissions. Moreover, due to the current energy crisis the need for the design of more powerful, fuel efficient, and environmentally friendly combustion systems is more and more highlighted. In addition to the influence on cement quality, pulverized coal combustion also affects the overall energy efficiency of the cement manufacturing process and the pollutant formation.

The combustion of coal can be considered, as a four step process: drying, devolatilisation process, combustion of char, and combustion of volatiles. In some extreme cases, different combustion stages may co-exist within a single particle (Backreedy et al., 2006).

\subsubsection{Drying process}

The evaporation of water vapour is related to the difference in water vapour concentration at the particle surface and in the gas:

$N_{\mathrm{w}}=k_{\mathrm{w}}\left(C_{\mathrm{p}}-C_{\mathrm{g}}\right)$,

where $N_{\mathrm{w}}$ is the molar flux of water vapour, $k_{\mathrm{w}}$ is the mass transfer coefficient, $C_{\mathrm{p}}$ is the water vapour concentration at the droplet surface, and $C_{\mathrm{g}}$ is the water vapour concentration in the gas.

The water vapour concentration at the droplet surface is evaluated by assuming that the partial pressure of water vapour at the particle surface is equal to the water saturation pressure $p_{\text {sat }}$, at the particle temperature $T_{\mathrm{p}}$ :

$C_{\mathrm{p}}=\frac{p_{\mathrm{sat}}}{R T_{\mathrm{p}}}$

where $R$ is the universal gas constant.

The concentration of vapour in the gas is known from solution of the following equation:

$C_{\mathrm{g}}=X_{\mathrm{H}_{2} \mathrm{O}} \frac{p}{R T}$,

where $X_{\mathrm{H}_{2} \mathrm{O}}$ is the local water mole fraction, $p$ is the local absolute pressure, and $T$ is the local temperature in the gas. The mass transfer coefficient is calculated from the Sherwood number correlation (Ranz and Marshall, 1952a,b):

$S h_{A B}=\frac{k_{\mathrm{w}} d_{\mathrm{p}}}{D_{\mathrm{w}}}=2.0+0.6 R e_{\mathrm{p}}^{1 / 2} S c^{1 / 3}$,

where $d_{\mathrm{p}}$ is the particle diameter, $R e_{\mathrm{p}}$ is the particle Reynolds number, and $S c$ is the Schmidt number. The Schmidt number is calculated according the following equation:

$S c=\frac{\mu}{\rho D_{\mathrm{w}}}$,

where $\mu$ is the dynamic viscosity, $\rho$ is the density, and $D_{\mathrm{w}}$ is the diffusion coefficient of water vapour in the gas.

The water vapour flux becomes a source of water vapour in the gas phase species transport equation, and the mass flux of water vapour multiplied by the latent heat becomes a source in the energy equation.

$m_{\mathrm{p}} c_{\mathrm{p}} \frac{\mathrm{d} T_{\mathrm{p}}}{\mathrm{d} t}=\alpha A_{\mathrm{p}}\left(T_{\mathrm{g}}-T_{\mathrm{p}}\right)+\varepsilon_{\mathrm{p}} \sigma A_{\mathrm{p}}\left(T_{\mathrm{g}}^{4}-T_{\mathrm{p}}^{4}\right)+\frac{\mathrm{d} m_{\mathrm{p}}}{\mathrm{d} t} h_{\text {latent }}$.

In Eq. (8), $m_{\mathrm{p}}$ is the particle mass, $c_{\mathrm{p}}$ is the particle heat capacity, $T_{\mathrm{p}}$ is the particle temperature, $T_{\mathrm{g}}$ is the surrounding gas temperature, $A_{\mathrm{p}}$ is the particle surface area, $\alpha$ is the convective heat transfer coefficient, $\varepsilon_{\mathrm{p}}$ is the particle emissivity, $\sigma$ is the Stefan-Boltzmann constant, and $h_{\text {latent }}$ is the latent heat.

When the particle reaches the boiling temperature, i.e. $100{ }^{\circ} \mathrm{C}$, the boiling process starts. During the whole boiling process particle temperature remains the same, until the entire capillary bounded water is vaporized (Agraniotis et al., 2010).

\subsubsection{Devolatilisation process}

For devolatilisation a single rate expression is used meaning that the devolatilisation rate $\mathrm{d} c_{\text {coal }} / \mathrm{d} t$ is in a first order dependency on the amount of coal remaining in the particle (Eq. (9)).

$\frac{\mathrm{d} c_{\text {coal }}}{\mathrm{d} t}=-k_{1} y_{\text {coal }}$.

Here $y_{\text {coal }}$ is the mass fraction of coal remaining in the particle and $k_{1}$ is the kinetic rate defined by an Arrhenius type expression including a pre-exponential factor $\left(k_{0,1}\right)$ and an activation energy $\left(E_{1}\right)$ (Eq. (10)).

$k_{1}=k_{0,1} \exp \left(-E_{1} / R T_{\mathrm{p}}\right)$.

The values of the kinetic constants $\left(k_{0,1}-\right.$ the pre-exponential factor and $E_{1}$ - the activation energy) for devolatilisation of different coals are obtained from the literature (Görner, 1991). 


\subsubsection{Volatile combustion}

For the combustion of the volatiles released during the devolatilisation process, a detailed chemistry approach is used for each homogeneous reaction. The source terms in the species transport equations and in the gas phase energy equation, accounting for the gas phase reactions, are calculated with reaction rates depending on species concentrations and temperature, i.e. as defined by the Arrhenius law. The modelled homogeneous reactions include tar and $\mathrm{CO}$ oxidation, $\mathrm{NO}_{\mathrm{x}}$ formation and the combustion of methane (Mikulčić et al., 2013b).

\subsubsection{Char combustion}

Parallel to the devolatilisation, coal char is oxidized to form CO and $\mathrm{CO}_{2}$ taking into account a mechanism factor depending on char particle size and temperature.

$\mathrm{C}+\frac{1}{f_{\mathrm{m}}} \mathrm{O}_{2} \stackrel{-395 \mathrm{~kJ} / \mathrm{mol}}{-110 \mathrm{~kJ} / \mathrm{mol}} \underset{\longrightarrow}{\longrightarrow}\left(2-\frac{2}{f_{\mathrm{m}}}\right) \mathrm{CO}+\left(\frac{2}{f_{\mathrm{m}}}-1\right) \mathrm{CO}_{2}$.

In Eq. (11), $f_{\mathrm{m}}$ represents the mechanism factor, which ranges between 1 and 2, and is calculated by the following expressions:

$f_{\mathrm{m}}=\frac{2 f_{\mathrm{CO}}+2}{f_{\mathrm{CO}}+2} ; \quad d_{\mathrm{p}}<50 \mu \mathrm{m}$,

$f_{\mathrm{m}}=\frac{2 f_{\mathrm{CO}}+2}{f_{\mathrm{CO}}+2}-\frac{f_{\mathrm{CO}}\left(d_{\mathrm{p}}-50\right)}{\left(f_{\mathrm{CO}}+2\right) \cdot 950} ; \quad 50 \mu \mathrm{m}<d_{\mathrm{p}}<1000 \mu \mathrm{m}$.

Here $d_{p}$ is the particle diameter, and the temperature dependence $f_{\mathrm{CO}}$ is defined as (Arthur, 1951)

$f_{\mathrm{CO}}=2500 \cdot \exp (-6240 / T)$,

where $T$ is the temperature.

Char combustion (Eq. (11)) is modelled according to the kinetics/ diffusion limited reaction model of Baum and Street (1971). The model assumes that the reaction rate of char combustion is limited either by the kinetics of the heterogeneous reaction $k_{2}^{\text {ch }}$ or by the oxygen's diffusion into the particle's mass expressed by the value of $k_{2}^{\mathrm{ph}}$ as presented in Eqs. (15)-(18).

$\frac{\mathrm{d} c_{\mathrm{c}}}{\mathrm{d} t}=-k_{2} A_{\mathrm{p}} p_{\mathrm{ox}} y_{\mathrm{c}}$

$k_{2}=\frac{k_{2}^{\mathrm{ch}} \cdot k_{2}^{\mathrm{ph}}}{k_{2}^{\mathrm{ch}}+k_{2}^{\mathrm{ph}}}$

$k_{2}^{\mathrm{ch}}=k_{0,2}^{\mathrm{ch}} \cdot \exp \left(-E_{2}^{\mathrm{ch}} / R T\right)$

$k_{2}^{\mathrm{ph}}=\frac{24 \cdot f_{\mathrm{m}} \cdot D_{0}}{R \cdot d_{\mathrm{p}} \cdot T_{0}^{1.75}} T^{0.75} \cdot 10^{5}$

In Eq. (15) the char reaction rate $\mathrm{d} c_{\mathrm{c}} / \mathrm{d} t$ in terms of rate of change of mass fraction is given. Here $y_{c}$ is the mass fraction of char remaining in the particle, $A_{\mathrm{p}}$ is the specific particle surface area, $p_{\mathrm{ox}}$ is the oxygen partial pressure, and $k_{2}$ is the overall kinetic rate of char combustion. In Eq. (16) the kinetics of the heterogeneous reaction $k_{2}^{\text {ch }}$ is defined as an Arrhenius type expression with a preexponential factor $k_{0,1}^{\text {ch }}$ and activation energy $E_{2}^{\text {ch }}$. In Eq. (18) $D_{0}$ is the oxygen diffusion coefficient, $d_{\mathrm{p}}$ is the particle diameter, and $T_{0}$ is the reference temperature. The values of the kinetic constants for the char combustion model are obtained from the literature (Görner, 1991).

\section{Computational details}

A complex geometry cement calciner used in the cement plant Lukavac, Bosnia and Herzegovina, was simulated and analyzed. Fig. 1 shows the calculated calciner's three dimensional geometry and the boundary conditions used in the CFD simulation. The calciner is $75 \mathrm{~m}$ high in total. The lower part of the calciner consists of two vertical tubes, of which one is used as the tertiary air inlet, and the other is used as an inlet for the hot flue gases coming from the rotary kiln. At the bottom of each of these tubes, inlets for coal and pre-dried limestone are positioned. Both tubes have an approximate diameter of $2 \mathrm{~m}$, and they connect at the height of $25 \mathrm{~m}$ to form a rectangular shaped junction, where tertiary air and hot flue gases coming from the rotary kiln, together with the introduced limestone and coal particles, are mixed. After the rectangular shaped junction a single vertical tube, with diameter of $3.1 \mathrm{~m}$, serves to direct the flow to the top of the calciner. The top of the calciner is designed in a way that it, by using the swirling effect, directs the upward stream to a downward stream. Finally after the flow is directed downwards, a tube, with diameter of $3.1 \mathrm{~m}$, is used to direct the fluid flow together with now already calcined raw

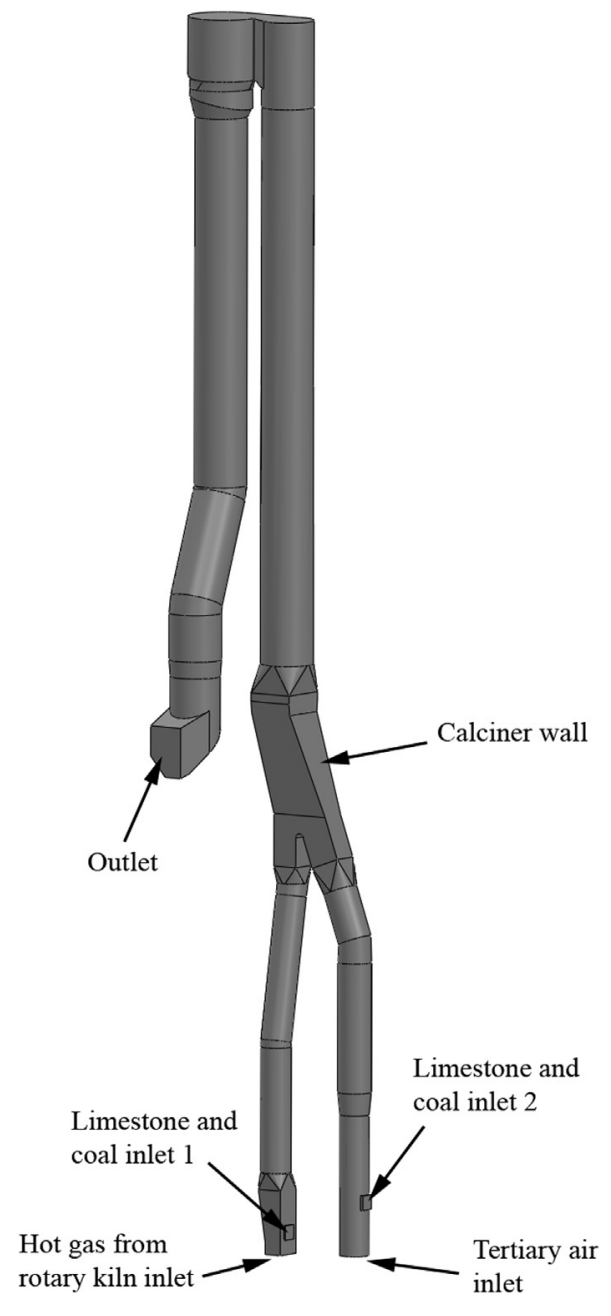

Fig. 1. Cement calciner's geometry and boundary conditions. 
Table 1

Boundary conditions.

\begin{tabular}{|c|c|c|c|c|c|c|c|c|}
\hline Notation & & Mass flow rate $[\mathrm{kg} / \mathrm{h}]$ & $T\left[{ }^{\circ} \mathrm{C}\right]$ & $\rho\left[\mathrm{kg} / \mathrm{m}^{3}\right]$ & $d_{\mathrm{p}}[\mu \mathrm{m}]$ & $\mathrm{O}_{2}$ [mass \%] & $\mathrm{N}_{2}$ [mass \%] & $\mathrm{CO}_{2}[$ mass $\%]$ \\
\hline \multirow[t]{2}{*}{ Limestone and coal inlet 1} & Coal & 5800 & 70 & 1300 & 50 & & & \\
\hline & Limestone & 126,000 & 780 & 3100 & 50 & & & \\
\hline \multirow[t]{2}{*}{ Limestone and coal inlet 2} & Coal & 1380 & 70 & 1300 & 50 & & & \\
\hline & Limestone & 21,000 & 780 & 3100 & 50 & & & \\
\hline Tertiary air inlet & & 20,690 & 780 & 1.292 & & 28 & 71.8 & 0.2 \\
\hline Hot gas from rotary kiln inlet & & 48,275 & 1060 & 1.292 & & 8 & 72 & 20 \\
\hline Outlet & Static pressure & $10^{5} \mathrm{~Pa}$ & & & & & & \\
\hline
\end{tabular}

material to the outlet of the calciner. The outlet of the calciner corresponds to the inlet of the fifth preheater cyclone, where measurement data are obtained. The total calciner volume is $603 \mathrm{~m}^{3}$.

The computational domain consists of 160,000 cells, which were employed to discretize the computational domain. The differencing scheme used for momentum, continuity and enthalpy balances was MINMOD Relaxed (FIRE, 2011) and for turbulence and scalar transport equations an Upwind scheme was applied. Turbulence was modelled by the standard $k-\varepsilon$ model. The P-1 radiation model was employed to model the radiative heat transfer. The P-1 radiation model takes into account the radiative heat exchanges between gas and particles, and is accurate in numerical simulations of pulverized coal combustion with radiation scattering (Sazhin et al., 1996). It has some disadvantage but it is advantageous in a way that it is easily applicable to the complicated geometries, like the one used in this study. The boundary conditions used for the cement calciner's simulation are given in Table 1 . The values given in Table 1 were the input data that were provided to the authors.

The coal used in the cement plant Lukavac, comes from the coal quarry located close to the cement plant. Its composition was the input data that was provided to the authors. The proximate and ultimate analysis of used coal is tabulated in Table 2.

\section{Result and discussion}

CFD is an effective tool for the investigation of the multiphase flow inside the cement calciner. The results showed some interesting features of the flow, which help to understand the operating conditions of the simulated calciner.

Fig. 2 shows the flow streamlines inside the calculated calciner. As can be observed, in the lower part of the calciner, in the tertiary air tube and the hot flue gases coming from the rotary kiln tube, the flow streams are stable and uniform, and going upwards. Both streams join together in the rectangular shaped junction, after which they form one stream that is going upwards to the top of the calciner. In this part of the calciner the majority of the limestone thermal degradation, e.g. calcination process, occurs. At the top of the calciner, where the fluid flow changes the direction, from an upward to a downward direction, the flow becomes highly swirled. The reason for this highly swirled flow is the big mass flow of the stream that is coming to the top of the calciner and the design of the

Table 2

Proximate and ultimate analysis of the used coal.

\begin{tabular}{lrlr}
\hline Proximate (\%wt raw) & & \multicolumn{2}{l}{ Ultimate (\%wt daf) } \\
\hline Moisture & 7.64 & $\mathrm{C}$ & 77.94 \\
Volatile matter & 15.38 & $\mathrm{H}$ & 5.07 \\
Fixed carbon & 32.16 & $\mathrm{O}$ & 1.69 \\
Ash & 44.82 & $\mathrm{~N}$ & 13.87 \\
Lower heating value (MJ/kg) & 23.34 & $\mathrm{~S}$ & 1.43 \\
\hline
\end{tabular}

calciner's top, that by using the swirling effect effectively changes the flow direction. After the flow is directed downwards, the flow gradually loses its swirling effect and together with now already calcined raw material goes to the outlet of the calciner. Understanding of the flow characteristics inside the calciner is of crucial 

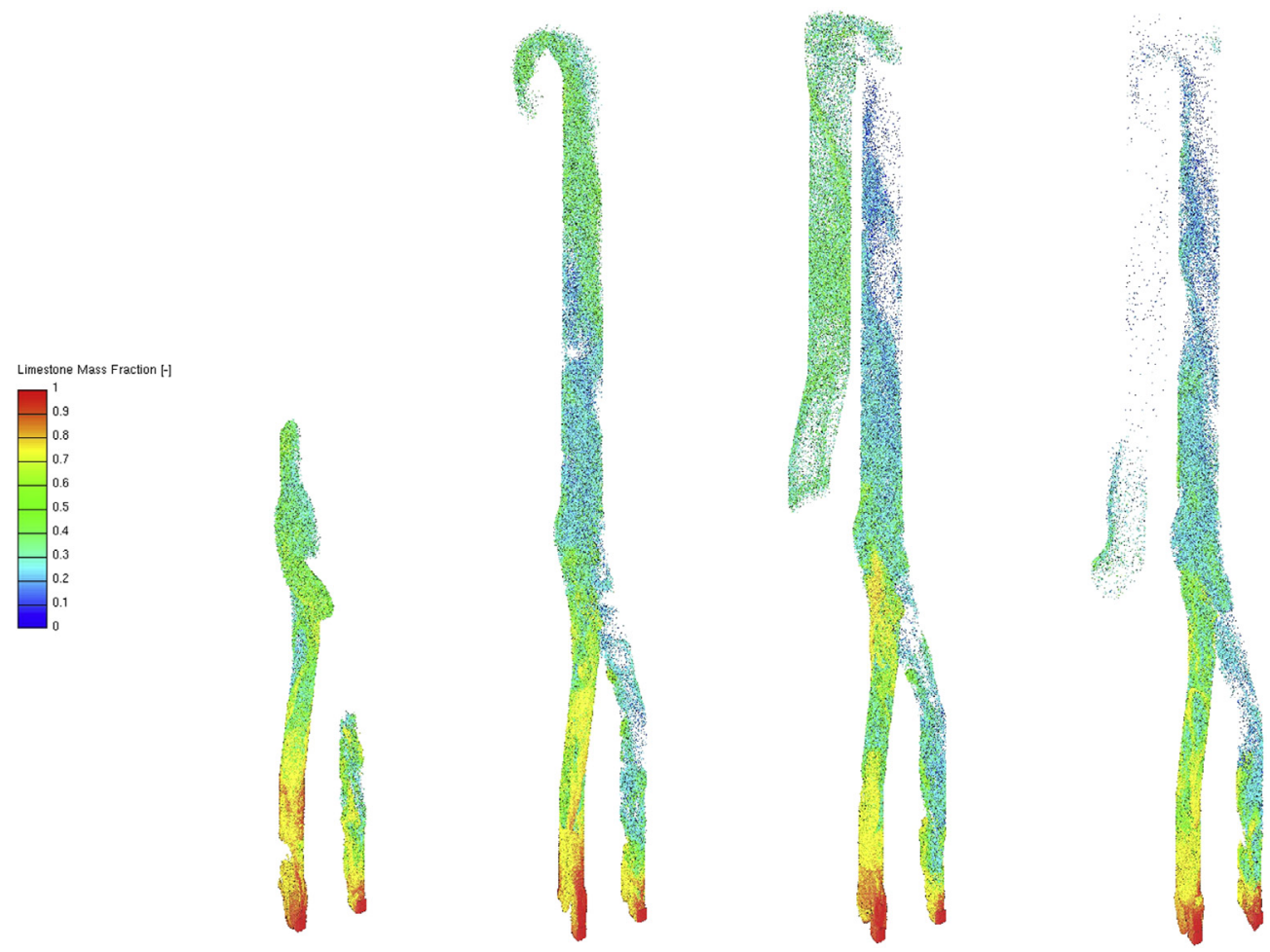

Fig. 3. Limestone degradation at different particle residence time: $2 \mathrm{~s}$ (left); $4 \mathrm{~s}$ (second from left); $6 \mathrm{~s}$ (second from right); $8 \mathrm{~s}$ (right).

importance for plant operators, since the flow characteristics give a good estimation of the particle residence time. The particle residence time is important, since limestone and coal need several seconds to fully decompose and burn.

Fig. 3 shows, from the left hand side to the right hand side, the position of limestone particles and its degradation at 2, 4, 6 and $8 \mathrm{~s}$ of particle residence time. For each particle residence time, the limestone mass fraction in particles is shown. It can be seen that limestone particles need several seconds to fully decompose.

Fig. 4 shows, from the left hand side to the right hand side, the position of produced lime particles at 2, 4, 6 and $8 \mathrm{~s}$ of particle residence time. For each particle residence time, the lime mass

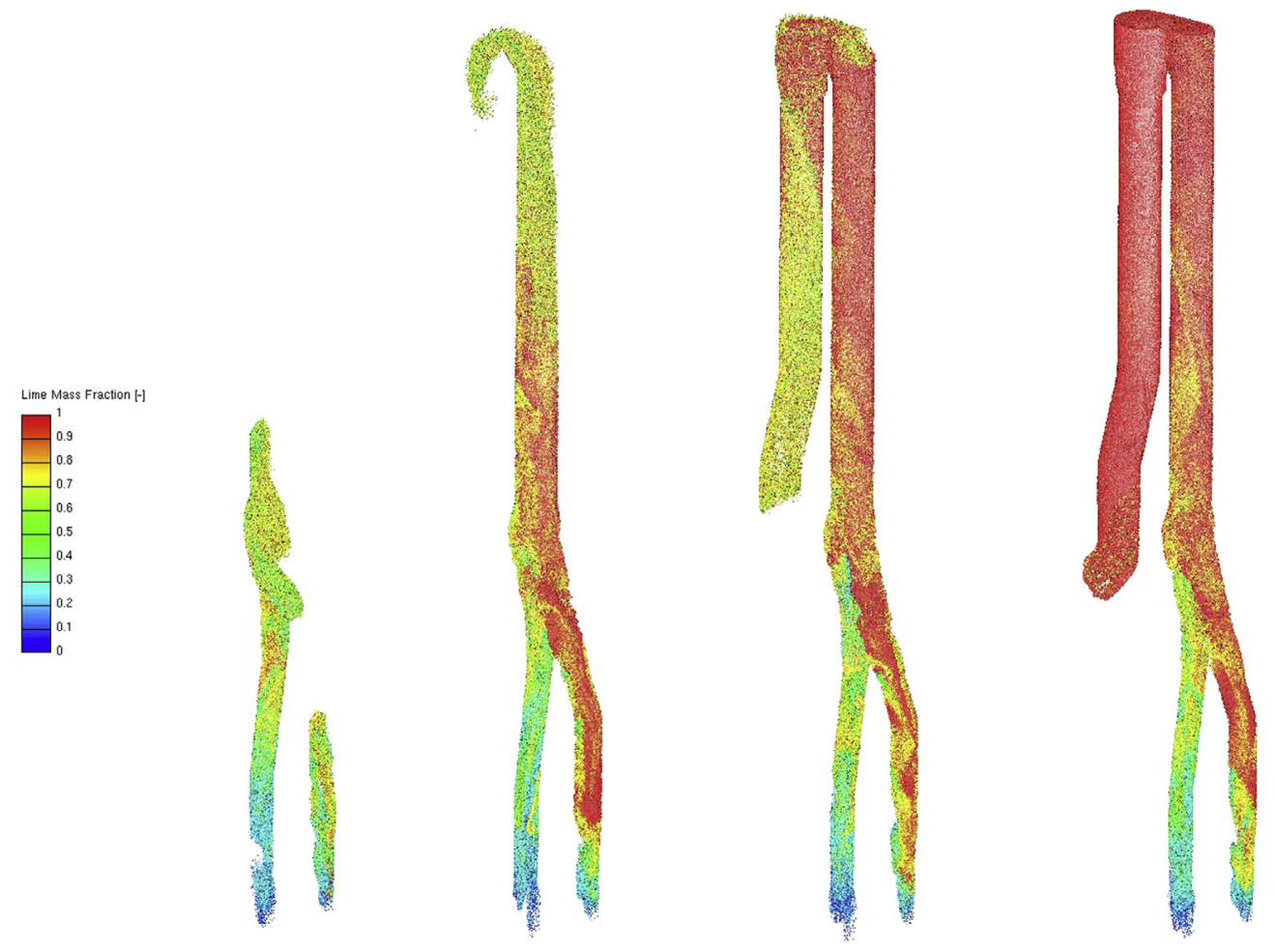

Fig. 4. Lime production at different particle residence time: $2 \mathrm{~s}$ (left); $4 \mathrm{~s}$ (second from left); $6 \mathrm{~s}$ (second from right); $8 \mathrm{~s}$ (right). 


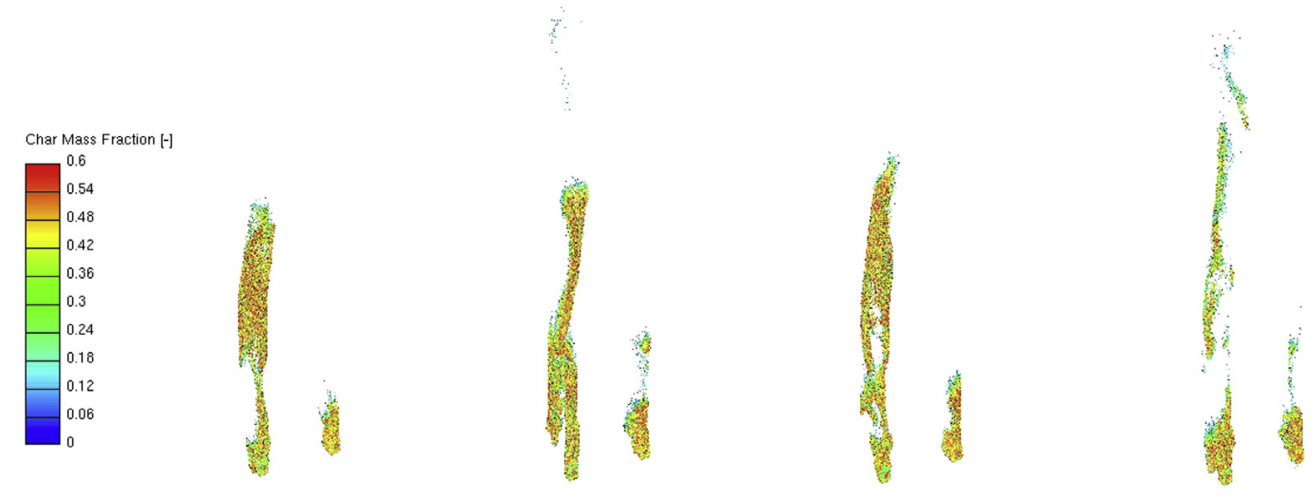

Fig. 5. Char oxidation at different particle residence time: $2 \mathrm{~s}$ (left); $4 \mathrm{~s}$ (second from left); $6 \mathrm{~s}$ (second from right); $8 \mathrm{~s}$ (right).

fraction in particles is shown. When compared to Fig. 3, the corresponding increase of the lime mass fraction at different particle residence time can be observed. In this figure, like in the previous one, it can be observed that the calcination process needs several seconds to finish.

Fig. 5 shows, from the left hand side to the right hand side, the position of char particles in the lower calciner part at 2, 4, 6 and $8 \mathrm{~s}$ of particle residence time. For each particle residence time, the char mass fraction in particles is shown. As can be observed, char particles combust in the lower part of the calciner, e.g. in two vertical tubes, of which one is used as the tertiary air inlet, and the other is used as an inlet of hot flue gases coming from the rotary kiln. Here it can be seen that unlike the calcination process, the char oxidation is a faster reaction and it does not need several seconds to fully react.

In Fig. 6 the particle residence time is shown. Due to increased environmental awareness, but also by increased environmental restrictions, plant operators and practical engineers are increasingly being interested in efficient cement production. Particle residence time is an important parameter for stabile and efficient operating cement calciner. As it was seen in previous figures raw material needs several seconds to fully decompose, by knowing the particle residence time inside the cement calciner plant operators can adjust the operating conditions for a more efficient operating calciner.

Due to the complex geometry of the calculated calciner, it is difficult to represent the concentration of species and the temperature field. For that reason, the back view of the calciner is shown in Figs. 7 and 8. Fig. 7 shows the combustion process inside the calculated calciner. The char mass fraction in particles is presented on the left hand side, in middle the temperature field is presented, and on the right side the ash mass fraction in particles is presented. Also the distribution of char and ash particles inside the calculated calciner is shown. The 'empty' regions for char mass fraction indicate the regions where conversion of char to $\mathrm{CO}, \mathrm{CO}_{2}$, and ash, to a large extent, has already been completed. In this figure the decrease of char mass fraction and the corresponding increase of ash mass fraction towards the outlet can be observed. Also, it can be seen that since the calcination process is a strong endothermic reaction, throughout the cement calciner the temperature field is uniform and there are no extreme temperature peaks inside the calciner. When looking at the shown temperature field, it can be

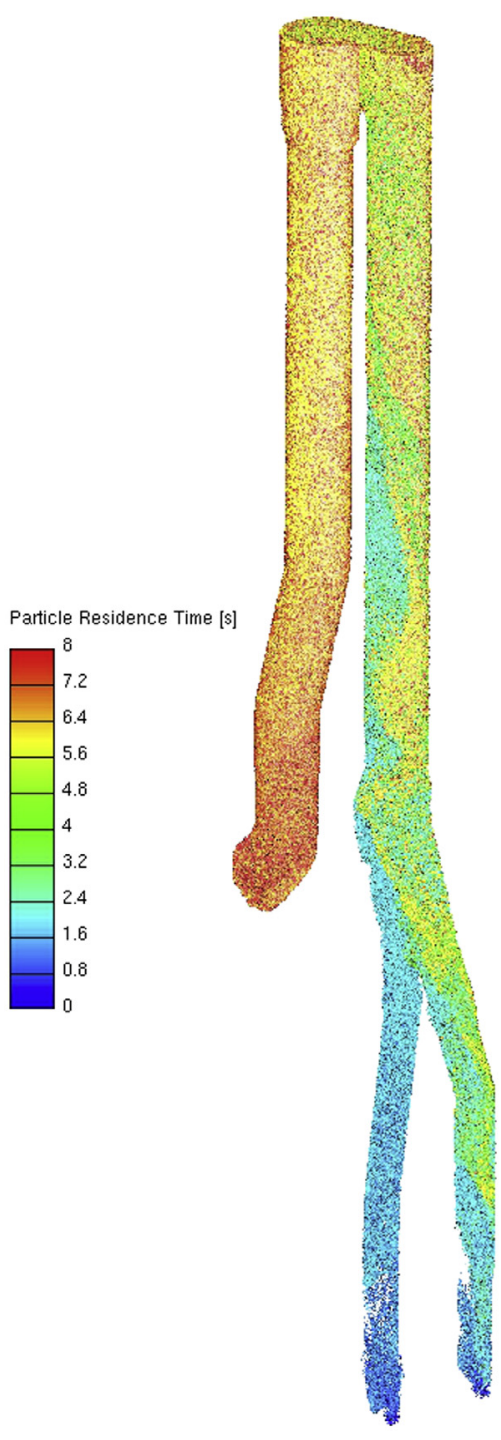

Fig. 6. Particle residence time. 
observed that calcination process lowers the temperature, and in that way lowers the thermal load on the calciner's walls. Furthermore, from Fig. 7 the distribution of char and ash particle can be observed. It can be seen that the char particles are concentrated close to the inlets, and that the ash particles are found in the whole calciner.

Fig. 8 shows the thermal degradation of limestone inside the calculated calciner. On the left hand side the limestone mass fraction in particles is shown, in middle the $\mathrm{CO}_{2}$ mass fraction is shown, and on the right hand side of the figure the produced lime mass fraction in particles is shown. It can be observed that as expected the limestone particles decompose from bottom of the calciner to its top and exit. The corresponding increase of the lime mass fraction can be observed on the right hand side of the figure. The mass fraction of lime in the particle increases as raw material particles move to the top of the calciner and its exit. The $\mathrm{CO}_{2}$ mass fraction shown in the middle of the figure shows that the highest concentrations are located at the bottom of the calciner where the combustion of coal occurs, and between the rectangular junction and the top of the calciner where most of the calcination process occurs.

Comparison of numerically obtained results with experimental data is essential for the validation of the numerical model used. The measurement equipment of this fully operating industrial calciner was placed on its outlet. On the outlet of the calciner, coal burnout rate, limestone degradation rate and the outlet temperature was measured. In Table 3, the comparison of measurement data and numerical predictions is shown. As can be seen, the numerical predictions are in good correlation with the measured data. Coal burnout rate is the same, whereas for the limestone degradation rate and the outlet temperature numerical predictions are slightly higher, but still in good agreement with the measured data.

The results presented herein show that computer simulation method can serve as an advanced tool to analyze and improve understanding of complex turbulent reacting flow in real cement calciner. The proposed models and methods can assist plant operators and practical engineers in the optimization of cement calciner's operating conditions, which are crucial to ensure better plant efficiency and reduction of pollutant emissions.

\section{Conclusion}

Computer modelling of the combustion and calcination processes provides a valuable tool that can be used for the investigation and better understanding of particle kinetics and pollutant emissions from cement combustion systems. A numerical model for the prediction of the flow, temperature field, calcination process, and pulverized coal combustion was presented. The numerical model of the pulverized coal combustion, as well as the numerical model of the calcination process, was implemented into a
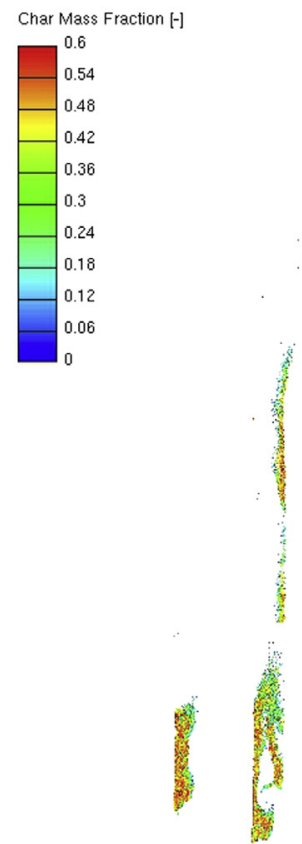
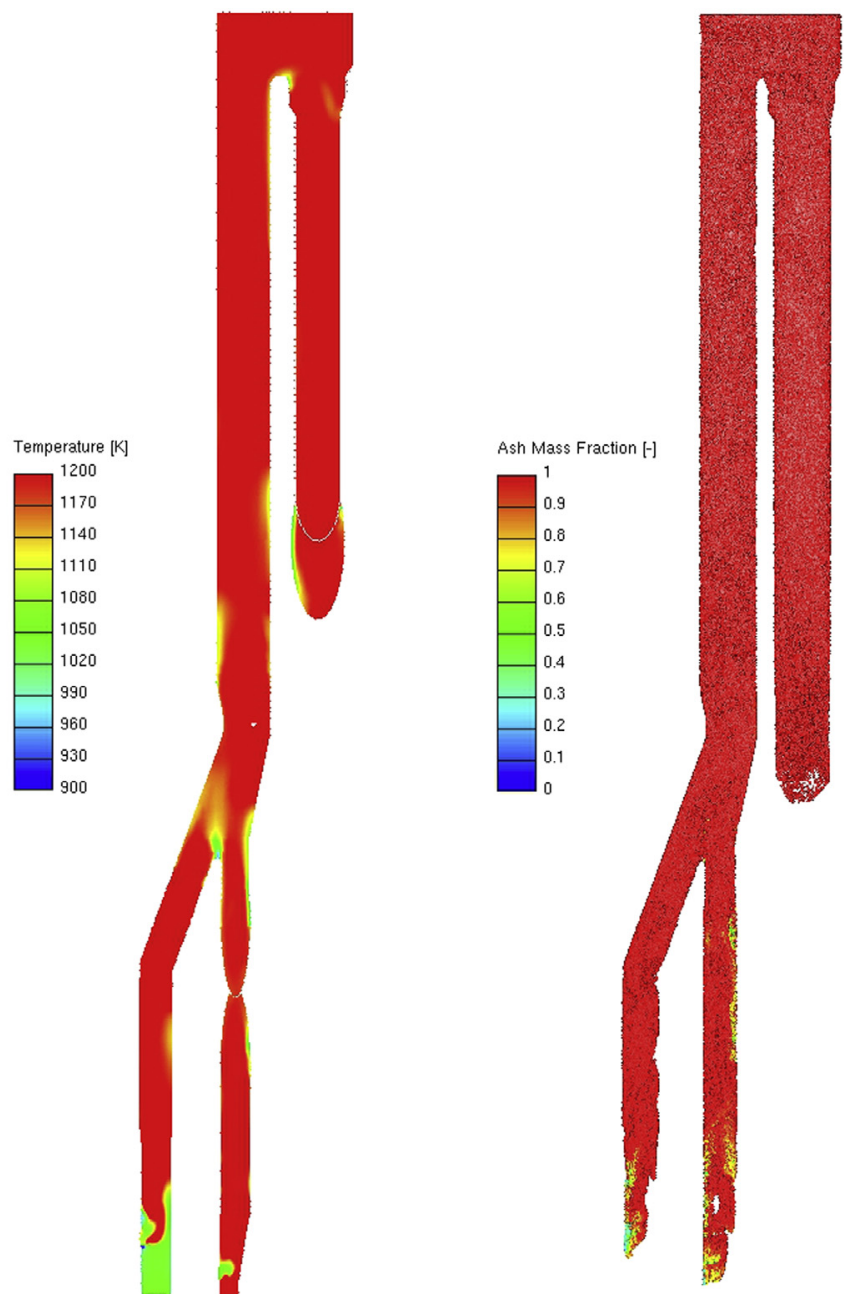

Fig. 7. Combustion process inside the calculated calciner. 


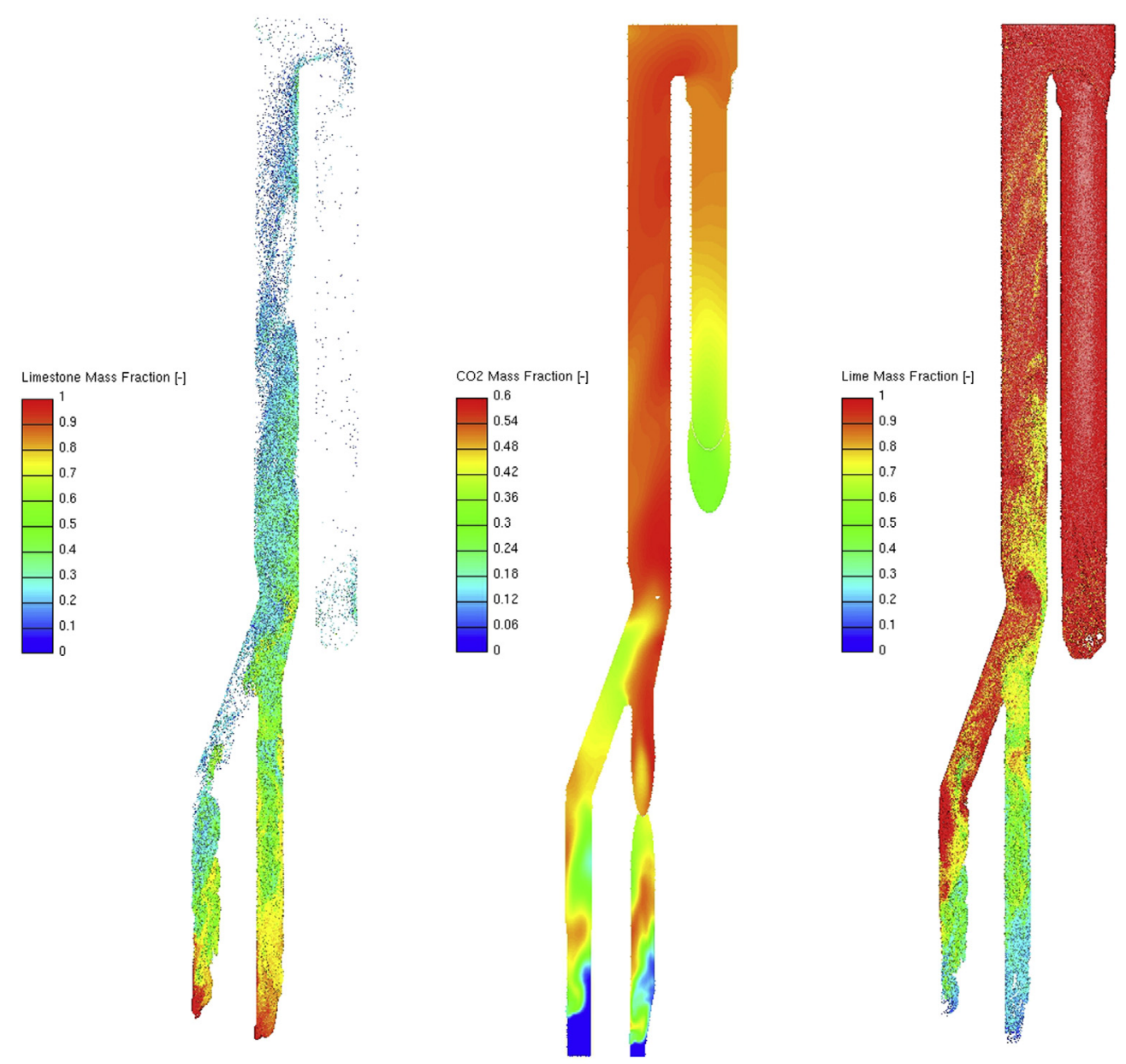

Fig. 8. Calcination process inside the calculated calciner.

commercial CFD code FIRE. The model takes into account the effects that dominate the named thermo-chemical reactions. For the pulverized coal combustion the effects of drying, the degradation during devolatilisation, generation of gaseous species and char oxidation are taken into account. For the calcination process the effects of decomposition pressure, temperature, diffusion, and particle porosity were taken into account. The model is detailed enough to contain the relevant physical and chemical processes, yet simple enough to run on the real industrial meshes needed for detailed CFD simulations of pyroprocessing units. The numerically obtained results were compared with available measurement data, and they are in good agreement. From the results shown it can be concluded that the presented model can be used for the investigation of reactive multiphase flows, and that numerical modelling can assist in the improvement of specific local conditions needed for the efficient calcination process. This paves the way for facilitating the reduction of pollutant emissions thus contributing to a more sustainable cement production.

Table 3

Comparison of measurement data and numerical predictions.

\begin{tabular}{lll}
\hline & $\begin{array}{l}\text { Measurement } \\
\text { data }\end{array}$ & $\begin{array}{l}\text { Numerical } \\
\text { predictions }\end{array}$ \\
\hline Coal burnout rate $[-]$ & 1.0 & 0.999 \\
Limestone degradation rate $[-]$ & 0.957 & 0.983 \\
Outlet temperature $[\mathrm{K}]$ & 1188 & 1213 \\
\hline
\end{tabular}

\section{Acknowledgements}

The authors wish to thank AVL List GmbH, Graz, Austria for the financing of the research project. Authors would also wish to thank Mr. E. von Berg, Dr. P. Priesching and Dr. R. Tatschl, from the CFD Development group at AVL-AST, Graz, Austria, for their continuous support and useful discussions during the development of numerical models used in this study.

The authors also wish to thank the management board, in particular Mr. Dž. Omerdić, of the cement plant Lukavac, Bosnia and Herzegovina, for providing the cement calciner's geometry for a CFD calculation, and input data needed for the calculation. Furthermore, the authors wish to thank Prof. Z. Osmanović from University of Tuzla for useful discussions.

\section{References}

Agraniotis, M., Nikolopoulos, N., Nikolopoulos, A., Grammelis, P., Kakaras, E., 2010. Numerical investigation of solid recovered fuels' co-firing with brown coal in large scale boilers - evaluation of different co-combustion modes. Fuel 89, 3693-3709.

Arthur, J.A., 1951. Reactions between carbon and oxygen. Trans. Faraday Soc. 47, $164-178$.

Backreedy, R.I., Fletcher, L.M., Ma, L., Pourkashanian, M., Williams, A., 2006. Modelling pulverised coal combustion using a detailed coal combustion model. Combust. Sci. Technol. 178, 763-787.

Baum, M.M., Street, P.J., 1971. Predicting the combustion behavior of coal particles. Combust. Sci. Technol. 3, 231-243.

Benhelal, E., Zahedi, G., Shamsaei, E., Bahadori, A., 2013. Global strategies and potentials to curb $\mathrm{CO}_{2}$ emissions in cement industry. J. Clean. Prod. 51, 142-161. 
Dou, H., Chen, Z., Huang, J., 2009. Numerical study of the coupled flow field in a Double-spray calciner. In: Proceedings - 2009 International Conference on Computer Modeling and Simulation, ICCMS 2009, pp. 119-123 art. no. 4797367.

Dovì, V.G., Friedler, F., Huisingh, D., Klemeš, I.J., 2009. Cleaner energy for sustainable future. J. Clean. Prod. 17, 889-895.

FIRE v2011 Manuals, 2011. Graz, Austria.

Görner, K., 1991. Technical Combustion Systems: Fundamentals, Modelling, Simulation. Springer-Verlag, Berlin, Heidelberg, Germany (in German).

Ha, S., Li, Y., Zhang, H., Shi, H.-Y., Zhu, C., 2010. Study on a separation technology for more efficient utilization of pulverized coals in cement plants. Fuel Process. Technol. 91, 1261-1266.

Hillers, M., Severin, T., Görner, K., Scherer, V., 2005. Process optimization for a precalciner facility of the cement industry. VDI Berichte 1888, 553-558 (in German).

IPCC (Intergovernmental Panel on Climate Change), 2007. IPCC Fourth Assessment Report. Cambridge University Press, Cambridge, United Kingdom and New York, NY, USA. Available at: www.ipcc.ch/publications_and_data/publications_and_ data_reports.shtml (accessed 06.11.13).

Klemeš, J.J., Varbanov, P.S., Pierucci, S., Huisingh, D., 2010. Minimising emissions and energy wastage by improved industrial processes and integration of renewable energy. J. Clean. Prod. 18, 843-847.

Klemeš, J.J., Varbanov, P.S., Huisingh, D., 2012. Recent cleaner production advances in process monitoring and optimization. J. Clean. Prod. 34, 1-8.

Mikulčić, H., von Berg, E., Vujanović, M., Priesching, P., Perković, L., Tatschl, R. Duić, N., 2012. Numerical modelling of calcination reaction mechanism for cement production. Chem. Eng. Sci. 69, 607-615.
Mikulčić, H., Vujanović, M., Duić, N., 2013a. Reducing the $\mathrm{CO}_{2}$ emissions in Croatian cement industry. Appl. Energy 101, 41-48.

Mikulčić, H., von Berg, E., Vujanović, M., Priesching, P., Tatschl, R., Duić, N., 2013b. Numerical analysis of cement calciner fuel efficiency and pollutant emissions. Clean. Technol. Environ. Policy 15, 489-499.

Nance, G., Abbas, T., Lowes, T., Bretz, J., 2011. Calciner design for lower CO and NOx using MI-CFD analysis to optimize "Hot-Reburn" conditions. In: IEEE Cement Industry Technical Conference (Paper) art. no. 5934552.

Oh, S.C., Kim, D.W., Yoon, J.Y., Byun, S.J., Kwon, W.-T., Kim, S.-R., Kim, H.T., 2004. Numerical analysis of turbulent gas-particle flow and coal combustion in a fluidized-bed calciner. J. Ind. Eng. Chem. 10, 208-214.

Ranz, W.E., Marshall Jr., W.R., 1952a. Evaporation from drops, Part I. Chem. Eng. Prog. 48, 141-146.

Ranz, W.E., Marshall Jr., W.R., 1952b. Evaporation from drops, Part II. Chem. Eng. Prog. 4, 173-180.

Sazhin, S.S., Sazhina, E.M., Faltsi-Saravelou, O., Wild, P., 1996. The P-1 model for thermal radiation transfer: advantages and limitations. Fuel 75, 289-294.

Wang, Y., Zhu, Q., Geng, Y., 2013. Trajectory and driving factors for GHG emissions in the Chinese cement industry. J. Clean. Prod. 53, 252-260.

Zhang, H., Dewil, R., Degrève, J., Baeyens, J., 2013. The design of cyclonic pre-heaters in suspension cement kilns. Int. J. Sustain. Eng. http://dx.doi.org/10.1080/ 19397038.2013.843605.

Zheng, J., Lu, H., Sun, X., He, Y., Ding, J., Wang, S., 2005. Hydrodynamic modeling of gas-particle flows in D-D calciners. Ind. Eng. Chem. Res. 44, 3033-3041. 